Published as:

Heikkinen TT, Lassila LVJ, Matinlinna J P, Vallittu PK Thermocycling effects on resin bond to silicatized and silanized zirconia, J ournal of Adhesion Science and Technology, 2009, v. 23(7-8)

p. $1043-1051$

\title{
THERMOCYCLING EFFECTS ON RESIN BOND TO SILICATIZED AND SILANIZED \\ ZIRCONIA
}

TIMO T. HEIKKINEN ${ }^{1}$, LIPPO V.J. LASSILA ${ }^{1}$, JUKKA P. MATINLINNA ${ }^{1,2}$, and PEKKA K. VALLITTU ${ }^{1}$

${ }^{1}$ Department of Prosthetic Dentistry and Biomaterials Science, Institute of Dentistry, University of Turku, Turku, Finland

${ }^{2}$ University of Hong Kong, Faculty of Dentistry, Dental Materials Science, Hong Kong, P.R. China

Correspondence:

Timo T. Heikkinen

Department of Prosthetic Dentistry and Biomaterials Science

Institute of Dentistry

University of Turku

Lemminkäisenkatu 2

FI-20250 Turku, FINLAND

Tel: +358172827050

E-mail: timppa.heikkinen@dnainternet.net

Running head: EFFECTS OF THERMOCYCLING ON BONDING TO Y-TZP 


\section{ABSTRACT}

Various techniques have been introduced to create a durable resin-composite bond to sintered zirconia (Y-TZP). Shear bond strength values achieved through tribochemical treatment have been studied in numerous studies, but less is reported about long-term durability.

The objective was to evaluate the effects of thermocycling and silane on shear bond strength of composite luting cement to silicatized Y-TZP. Two groups of Y-TZP (Procera Zirconia, Nobel Biocare), both consisting of 40 specimens were prepared. The specimen surfaces were air particle abraded by silica-coated aluminum trioxide particles (particle size $110 \mu \mathrm{m}$, duration $15 \mathrm{~s}$, air pressure $300 \mathrm{kPa}$, nozzle-distance $10 \mathrm{~mm}$ ). The silica-coated surfaces in group ZA were silanized with acrylate-functional silane (Experimental laboratory-made acrylate silane, Toray Dow Corning Silicone) and in the other group ZM with pre-activated methacrylate silane (ESPE Sil, 3M ESPE). The surfaces were coated with adhesive-system (Scotchbond 1, 3M ESPE) and photo-polymerized for $10 \mathrm{~s}$. Resin-composite luting cement (RelyX ARC, 3M ESPE) stubs were added onto substrates and photo-polymerized for $40 \mathrm{~s}$. The test specimens were thermocycled for $0,1000,3000,8000$ or 15000 times (temperature $5-55^{\circ} \mathrm{C}$, immersion time $20 \mathrm{~s}$ ). The shear bond strengths of luting cement to ceramics were measured with a cross-head speed of $1.0 \mathrm{~mm} / \mathrm{min}$. ANOVA was used as statistical analysis. ANOVA revealed that both silane and thermocycling affected significantly $(p<0.001)$ on shear bond strength. Short term hydrolytic stability of acrylate silane was superior. The conclusion: estimation of bonding requires extended thermocycling.

Keywords: Zirconia; Y-TZP; silicatization; silane; resin-composite; luting cement; shear bond strength. 


\section{INTRODUCTION}

Oxide ceramics, e.g. yttria stabilized zirconium dioxide (Y-TZP), have established their position as one possible substitute for metal alloys in restorative and prosthetic dentistry. Their usability is mainly based on their superior aesthetic properties; though there is available a wide variety of all kinds of clinical applications, such as root canal posts, crowns, veneers, fixed partial dentures, implants, and implant abutments [1]. Their excellent strength and lack of potentially allergenic and toxic metallic compounds [2] have been other arguments for their increasing use in prosthodontics as well. Resin-composite luting cements are commonly used to attach these structures to enamel and dentin.

In order to create a clinically stabile resin-composite bond to sintered, non-etchable ceramics, many kinds of bonding techniques have been studied, tested and introduced [3]. The shear bond strengths achieved by one of those, i.e. tribochemical treatment, have been studied in numerous studies. The procedure requires initial conditioning by silicatization $[4,5,6]$ followed by silanization with a silane coupling agent [7] in order to form a reactive surface for consequent bonding with adhesive resins. Tribochemistry all in all involves creating chemical bonds by applying kinetic energy [8], e.g. in the form of airborne particle abrasion, without any application of additional heat or light.

Tribochemical silica-coating by using $\operatorname{CoJet}^{\mathrm{TM}}$ (CoJet ${ }^{\mathrm{TM}}$, 3M ESPE, Seefeld, Germany) at the dentist's office is a widely used method for initial preparation of ceramic or metal alloy structure prior to reparation or cementing $[9,10]$. The system is a so-called tribochemical silicatization method because the energy needed for silicatization is transferred to the substrate material in the form of kinetic energy, which generates frictional heat at the impact focus. However, silicatization takes place macroscopically without any change in temperature [4]. The CoJet ${ }^{\mathrm{TM}}$ system is based on 
airborne micro-blasting with silica-modified aluminum trioxide. The outcome is that the system provides the ceramics with afresh, reactive silica-rich outer surface prone to the silanization reactions. Consequently, silane monomers react spontaneously with silica and glass [11]. The system provides also the following resin-composite adhesion for suitable luting cements. However, less attention has been paid to long term durability of tribochemically treated surface bonding values.

There are also available several luting cements based on, e.g. modern organophosphate resincomposites, that, unlike the products and methods dealt in the present study with, do not necessarily require silicatization nor silanization in order to be reactive and effective. Moreover, alternative conditioning methods for silicatization, such as selective infiltration of zirconia, have recently been introduced [12]. Still, the present study focuses on the tribochemical bonding relying on the bright future of the method and its variants.

In numerous studies thermo-cycling and varying times of water-storage have been used as an artificial ageing method [5, 12-16]. It is a well known fact that thermocycling is a controversial method and other methods have been suggested [17]. However, thermocycling is in accordance with the ISO 10477 standard concerning the ageing of the bond [18]. It is to be noted that there is no concrete evidence that failures in practice occur because of thermal stresses, notwithstanding the theoretical expectation. However, the distinction must be made between the equivalent static stress test and fatigue failure, where repeated loading to a stress below the static strength occurs. Respectively, it has never been determined whether it is the time at temperature, i.e. cumulative duration under stress, as opposed to true fatigue, that is relevant factor. In other words, whether failure occurs due to flow, i.e. deformation, in one or other of the layers in the bonded structure is unknown. This must be dependent on the glass transition temperatures $\left(T_{g}\right)$ of those bonded 
components which apparently have not been determined. Such flow would lead to collapse in a truly static test at a stress below the ordinary static strength. Cycling testing cannot as such discriminate these issues, and failure to allow for them might account in part for the inconsistency of test results so far reported. The test outcome depends on the stress generated and the failure mechanism [19]. 


\section{OBJECTIVES}

The aim of the present study was to evaluate the effect of thermocycling on the shear bond strength and to compare the effect of the use of two chemically different types of silanes on the shear bond strength of resin-composite luting cement to tribochemically conditioned and silanized Y-TZP. 


\section{MATERIALS AND METHODS}

All the materials used in the present study are presented on Table 1. Two groups of Y-TZP (Procera Zirconia, Nobel Biocare, Göteborg, Sweden), both formed by 40 specimens were prepared. Square shaped piece $(2 \mathrm{~mm} \times 10 \mathrm{~mm} \times 10 \mathrm{~mm})$ of ceramic material were embedded into plastic cylinders (diameter $20 \mathrm{~mm}$, height $10 \mathrm{~mm}$ ) and filled with acrylic resin to form the specimen and bonding substrate for the resin-composite stubs. The surfaces of the specimens were air particle abraded for 15 s by silica-coated aluminium trioxide particles (Rocatec ${ }^{\mathrm{TM}}$ Plus, 3M ESPE, Seefeld, Germany), $110 \mu \mathrm{m}$ in diameter. Air pressure of $300 \mathrm{kPa}$ was used to condition the surfaces. A distance of 10 $\mathrm{mm}$ between the tip of the blasting device and the substrate surface was maintained by a solid assembly of the blasting device above the substrate.

A 95.0 vol.-\% ethanol and 5.0 vol-\% de-ionized water (milli-Q water) blend was prepared. Its pH was adjusted with $1 \mathrm{M}$ acetic acid at 4.5 and then the solvent system was allowed to stabilize for 24 $\mathrm{h}$ at room temperature. 1.0 vol.-\% solution of 3-acryloyloxypropyltrimethoxysilane monomer was prepared in the acidified ethanol-water solution, in $50 \mathrm{~mL}$ polyethylene bottles. The silane was allowed to hydrolyze for $1 \mathrm{~h}$ at room temperature as described in literature [13, 14]. An unopened ESPE Sil which contains pre-activated 3-methacryloyloxypropyltrimethoxy silane was used as a control. Next, the silica-coated surfaces of zirconia group ZA were silanized with the acrylate silane. The other group ZM was silanized with a methacrylate silane (ESPE Sil, 3M ESPE, Seefeld, Germany). One coat of silane was applied with a fine brush and a new brush tip was used each time.

All the surfaces were next coated with an adhesive resin (Scotchbond 1, 3M ESPE, St. Paul MN, USA) and photo-polymerized for 10 s (Optilux 501, Kerr, Orange CA, USA). Resin-composite luting cement (RelyX ARC, 3M ESPE, St. Paul MN, USA) stubs (diameter $3.5 \mathrm{~mm}$, height $5.0 \mathrm{~mm}$ ) 
were formed by means of a plastic mold and a plunger inside the mold onto substrates and photopolymerized for $40 \mathrm{~s}$ (Optilux 501, Kerr, Orange CA, USA). The distance between the tip of the photo-polymerizer and the stub was controlled by pressing the tip on the plastic mold (height 10 $\mathrm{mm})$.

The specimens of both group ZA and ZM were randomly divided into five subgroups. The test specimens ( $\mathrm{n}=8$ /group) were thermocycled $0,1000,3000,8000$ or 15000 times between $55 \pm 1{ }^{\circ} \mathrm{C}$ and $5 \pm 1{ }^{\circ} \mathrm{C}$ (Thermocycling unit 81, custom-made, Biomechanical Testing Laboratory, University of Turku, Finland). Duration of immersion in both temperatures was $20 \mathrm{~s}$ at a time.

The shear bond strengths of the luting cement to the ceramics were measured with a crosshead speed of $1.0 \mathrm{~mm} / \mathrm{min}$ using universal materials testing device (Model LRX, Lloyd Instruments Ltd, Fareham, England) as in Figure 1 and the data were recorded using PC software (Nexygen 4.0, Lloyd Instruments Ltd, Fareham, England). The specimens were secured in a mounting jig (Bencor Multi-T shear assembly, Danville Engineering Inc., San Ramon, CA, USA) with the half circle shearing rod against and parallel to the resin-composite and ceramic interface. The data of shear bond strength values were analysed with analysis of variance (two-way ANOVA) using independent factors of silane and thermocycling. Tukey's post hoc test was carried out at significance level $(p<0.05)$ with SPSS 10.0 (Statistical Package for Social Science, SPSS Inc., Chicago IL, USA). 


\section{RESULTS}

Mean values of data of shear bond strengths are presented on Table 2. Additionally, the shear bond strength values have been presented as a function of thermocycling in Figure 2. ANOVA revealed that both factors, silane and thermocycling, affected significantly the shear bond strength.

There were considerable differences between bond strengths after extended thermal cycles among both groups. The shear bond strength values at dry condition were considerably higher for both materials than after aging of 1000, 3000 or 8000 cycles in thermocycler. Group ZA (acrylate silane) revealed superior results compared to group ZM (methacrylate silane) prior to 8000 cycles. However, after that the bond values of ZA were rapidly decreasing towards ZM showing similar values after 8000 and 15000 cycles. ZM groups revealed statistically $(\mathrm{p}<0.05)$ lower shear bond strength values prior to 8000 cycles compared to ZA ( $p<0.05)$ (Table 2). 


\section{DISCUSSION}

This study suggested that thermocycling considerably diminished the shear bond strength values measured between resin-composite luting cement and tribochemically conditioned Y-TZP. Postcuring due increased temperature during thermocycling has been reported to have an influence on bond strength values, but this study did not demonstrate any effect as enhanced bonding. Higher degree of conversion of resin composite also increases the glass transition of a polymer by introducing restrictions on the molecular motions of the chain [16]. Thus, the thermoset-based composites used as luting cements are well cross-linked after light-curing and hence in practice are more inert to post-curing by heat.

Furthermore, acrylate silane monomer (ZA) is more reactive, since it does not have the protecting methyl group, as methacrylate silane monomer (ZM) does. Acrylate silane was selected for this study, since it has been reported to produce higher shear bond strength values than methacrylate silane [13] and it was of great interest to evaluate long term stability of ZA in this test set-up. As silanes react, they form a branched, 3D polysiloxane film between the dissimilar matrices, ceramic and resin-composite. The film consists of siloxane, $\mathrm{Si}-\mathrm{O}-\mathrm{Si}$-, bonds and acrylate/methacrylate groups [11].

The experimental laboratory-made acrylate silane group ZA showed superior shear bond strength values in the initial condition compared with the methacrylate silane group ZM. After 1000 and 3000 rounds in thermocycler the same phenomenon was observed. However, after 8000 rounds both groups showed abundantly declined shear bond strength values indicating that thermocycling powerfully affects the bond between ceramic material and luting cement. Hence, the long-term durability of bond achieved by tribochemical treatment is arguable and needs further investigation. 
Conventional shear bond test is typical testing platform for evaluation adhesion, produces the nonuniform interfacial stress at cement-ceramic interface. Their specific fracture pattern may cause cohesive failure within the cement or the ceramics, which may lead to erroneous conclusions [3]. The difference of linear coefficient of thermal expansion (LCTE) of resin composite and ceramics may have an effect on the mechanism of failure at the ceramic-composite interface. LCTE of composite luting cements are approximately $40-60 \mu$-strain $/{ }^{\circ} \mathrm{C}$, whereas LCTE of ceramic materials are typically less than $10 \mu$-strain $/{ }^{\circ} \mathrm{C}$. This difference causes thermal stresses at the cement-ceramic interface, probably leading to unequal changes in dimensions, and eventually to fractures and failure. The difference between LCTE is particularly high between ceramics and initially flowable luting cements, which have lower filler content than conventional restorative filling resincomposites in order to improve the flow of the cement and to facilitate the fit of the prosthetic structure $[20,21]$. Moreover, hydroscopic expansion of luting cements presumably causes extra stresses at the interface of zirconia and cement as the water sorption of the resin composite increases [22].

According to the present study the effect of alternative silanes should also be taken into consideration when studying variables of tribochemical treatment. It may be possible to find new chemical combinations more favourable to be used as a durable substitute for methacrylatefunctional silane as some recent reports suggest $[14,15]$. It also might be useful to continue testing by using longer water-storage periods to evaluate the stability of the connecting and bonding silane layer to hydrolytic effects. Silane bonds are known to rearrange and reform. Water is always in practice present at molecular level in the siloxane film and there is not much published information of the hydrolytic stability of the siloxane bonding between the materials used in this study [7, 11]. 
Kern \& Wegner used short term water storage period and compared it to long time water storage period combined with 37500 thermocycling period, which may, regarding some materials, lead to spontaneous dissolution of the bond without any shear bond strength test. On the basis of their results the number of thermocycling seems to play an important role when considering the durability of the bond. Different materials seem to behave with variability during cycling as well. Thus, within the limitations of this study, it seems important to emphasize that extended cycles, along with long-term water storage at $37^{\circ} \mathrm{C}$, should be used when evaluating long term stability of the bond [23].

As previously mentioned, thermocycling has been criticized in what extend it mimics to clinical situation. ISO 10477 defines 6000 cycles, which may be insufficient for evaluating the long term stability. The temperatures and dwelling times used in the several studies have been criticized as well as the meaning of resting time and the frequency of cycling. While there is not concrete evidence that failures occur because of thermal stresses, the time at temperature, every kind of thermocycling tests remain arbitrary. Cycling tests cannot of themselves discriminate the type of the failure causing the collapse of bonding cement to zirconia. One possibility might be a less severe test which would improve the discrimination of the failure point as long as the stresses remain below those causing immediate collapse. However, the mechanism of the failure caused by cycling testing needs further investigation [19]. 


\section{CONCLUSIONS}

Within the limitations of this in vitro study, the following conclusions can be drawn:

1. Short term hydrolytic stability of acrylate silane was superior to methacrylate silane.

2. Extended aging by thermocycling and water-storage are needed in order to evaluate the true benefit of different silanes for enhancement of bonding capacity of resin-composite luting cement. 


\section{ACKONWLEDGEMENTS}

The authors wish to thank Nobel Biocare and 3M ESPE for their generous supply of test materials. This investigation was financially supported by grants from Finnish Dental Society Apollonia and Turku University Foundation. The research was also a part of the NIOM Biomaterials network cooperation in the Nordic countries. 


\section{REFERENCES}

1. B. Ardlin, Dent. Mater. 18, 590-595 (2002).

2. J. C. Wataha, J. Prosthet. Dent. 83, 223-234 (2000).

3. $\quad$ M. B. Blatz, A. Sadan and M. Kern, J. Prosthet. Dent. 89, 268-274 (2003).

4. R. Guggenberger, Dtsch. Zahnarztl. Z. 44, 874-876 (1989).

5. M. Ozcan and P. K. Vallittu, Dent. Mater. 19, 725-731 (2003).

6. $\quad$ M. Kern and V. P. Thompson, J. Dent. 22(5), 300-306 (1994).

7. J. P. Matinlinna, L. V. Lassila, M. Ozcan, A. Yli-Urpo and P. K. Vallittu, Int. J. Prosthodont. 17, 155-164 (2004).

8. $\quad$ C. K. Kajdas, Trib. Int. 38, 337-353 (2005).

9. T. T. Heikkinen, L. V. J. Lassila, J. P. Matinlinna and P. K. Vallittu, Acta Odont. Scand. 65, 241-248 (2007).

10. R. Amaral, M. Özcan, L. F. Valandro, I. Balducci, M. A. Bottino, J. Biomed. Mater. Res. B Appl. Biomater. 85B 1-9 (2007) 
11. E. P. Plueddemann, Mod Plast 3, 92-98 (1970).

12. M. N. Aboushelib, C. J. Kleverlaan and A. J. Feilzer, J. Prosthet. Dent. 98, 379-388 (2007).

13. J. P. Matinlinna, L. V. J. Lassila and P. K. Vallittu, J. Dent. 34, 740-746 (2006).

14. J. P. Matinlinna, L. V. J. Lassila and P. K. Vallittu, Dent. Mater. 23, 1173-1180 (2007).

15. J. P. Matinlinna, L. V. J. Lassila and P. K. Vallittu, Acta Odontol. Scand. 65, 44-51 (2007).

16. G. Meric and I. E. Ruyter, Dent. Mater. 23, 1157-1163 (2007).

17. R. van Noort, S. Noroozi, I. C. Howard and G. Cardew, J. Dent. 17, 61-67 (1989).

18. ISO 10477 International Organization for Standardization: Dentistry-Polymer-Based Crown and Bridge Materials, ISO 10477, Amendment: 1996.

19. M. S. Gale and B. W. Darvell, J. Dent. 27, 89-99 (1999).

20. A. Tezvergil, L. V. J. Lassila and P. K. Vallittu, Dent. Mater. 19, 471-477 (2003). 
21. G. Meric and I. E. Ruyter, Dent. Mater. 24, 1050-1057 (2008).

22. I. D. Sideridou, M. M. Karabela and E. C. Vouvoudi, Dent. Mater. 24, 1131-1136 (2008)

23. M. Kern and S. M. Wegner, Dent. Mater. 14, 64-71 (1998). 
Table 1. Materials used in this study.

\begin{tabular}{|c|c|c|c|}
\hline Brand & Manufacturer & Chemical composition & Batch number \\
\hline Procera Zirconia & $\begin{array}{l}\text { Nobel Biocare, Göteborg, } \\
\text { Sweden }\end{array}$ & $\begin{array}{l}\text { Yttria stabilized } \\
\text { zirconium dioxide } \\
\text { (Y-TZP) }\end{array}$ & $\mathrm{N} / \mathrm{A}$ \\
\hline Rocatec $^{\mathrm{TM}}$ Plus & 3M ESPE, Seefeld, Germany & $\begin{array}{l}\text { Silica-coated aluminium } \\
\text { trioxide, particle } \varnothing 110 \mu \mathrm{m}\end{array}$ & 305 \\
\hline $\begin{array}{l}\text { Experimental laboratory } \\
\text { made acrylate silane }\end{array}$ & $\begin{array}{l}\text { Toray Dow Corning Silicone, } \\
\text { Tokyo, Japan }\end{array}$ & $\begin{array}{l}\text { 3-Acryloyloxypropyltri- } \\
\text { methoxysilane, } 1.0 \text { vol.- } \%\end{array}$ & THJM010206 \\
\hline ESPE Sil & 3M ESPE, Seefeld, Germany & $\begin{array}{l}\text { 3-Methacryloyloxypropyltr } \\
\text { methoxysilane, } \\
\text { ca. } 1.0-2.0 \text { vol.- } \%\end{array}$ & 142104 \\
\hline Scotchbond 1 & 3M ESPE, St. Paul MN, USA & $\begin{array}{l}\text { Water, ethanol, } \\
\text { HEMA, BisGMA, } \\
\text { dimethacrylates, } \\
\text { polyalkeonic acid, } \\
\text { copolymers, } \\
\text { photoinitiator }\end{array}$ & $3 \mathrm{JK}$ \\
\hline RelyX ARC & 3M ESPE, St. Paul MN, USA & $\begin{array}{l}\text { Water, ethanol } \\
\text { 2-HEMA, BisGMA, } \\
\text { GDMA, HEMA, TMDI, } \\
\text { copolymer of acrylic, } \\
\text { itaconic acids, } \\
\text { DDMA }\end{array}$ & 20040130 \\
\hline
\end{tabular}


Table 2. Mean values of shear bond strengths with standard deviations as a function of thermal cycles.

\begin{tabular}{|l|l|l|l|l|l|}
\hline \multirow{2}{*}{ Group } & \multicolumn{5}{|c|}{ Thermal cycles $\left(+5 \pm 1{ }^{\circ} \mathbf{C}\right.$ and $\left.+55 \pm 1{ }^{\circ} \mathbf{C}\right)$} \\
\cline { 2 - 6 } & $\mathbf{0}$ & $\mathbf{1 0 0 0}$ & $\mathbf{3 0 0 0}$ & $\mathbf{8 0 0 0}$ & $\mathbf{1 5 0 0 0}$ \\
\hline ZA & $23.0 \pm 6.7^{\mathrm{a}}$ & $20.8 \pm 5.5^{\mathrm{ab}}$ & $13.5 \pm 7.0^{\mathrm{b}}$ & $4.7 \pm 1.4^{\mathrm{c}}$ & $4.7 \pm 2.7^{\mathrm{c}}$ \\
\hline ZM & $16.8 \pm 4.2^{\mathrm{a}}$ & $10.2 \pm 5.1^{\mathrm{bc}}$ & $6.9 \pm 4.0^{\mathrm{bc}}$ & $4.4 \pm 1.8^{\mathrm{c}}$ & $2.7 \pm 1.2^{\mathrm{c}}$ \\
\hline p (within cycles) & 0.058 & 0.002 & 0.056 & 0.723 & 0.105 \\
\hline
\end{tabular}

Same superscript letter within row indicates homogenous subset (Tukey, $\mathrm{p}>0.05$ ). 
Figure 1. The shear bond strength test jig in the universal testing machine.

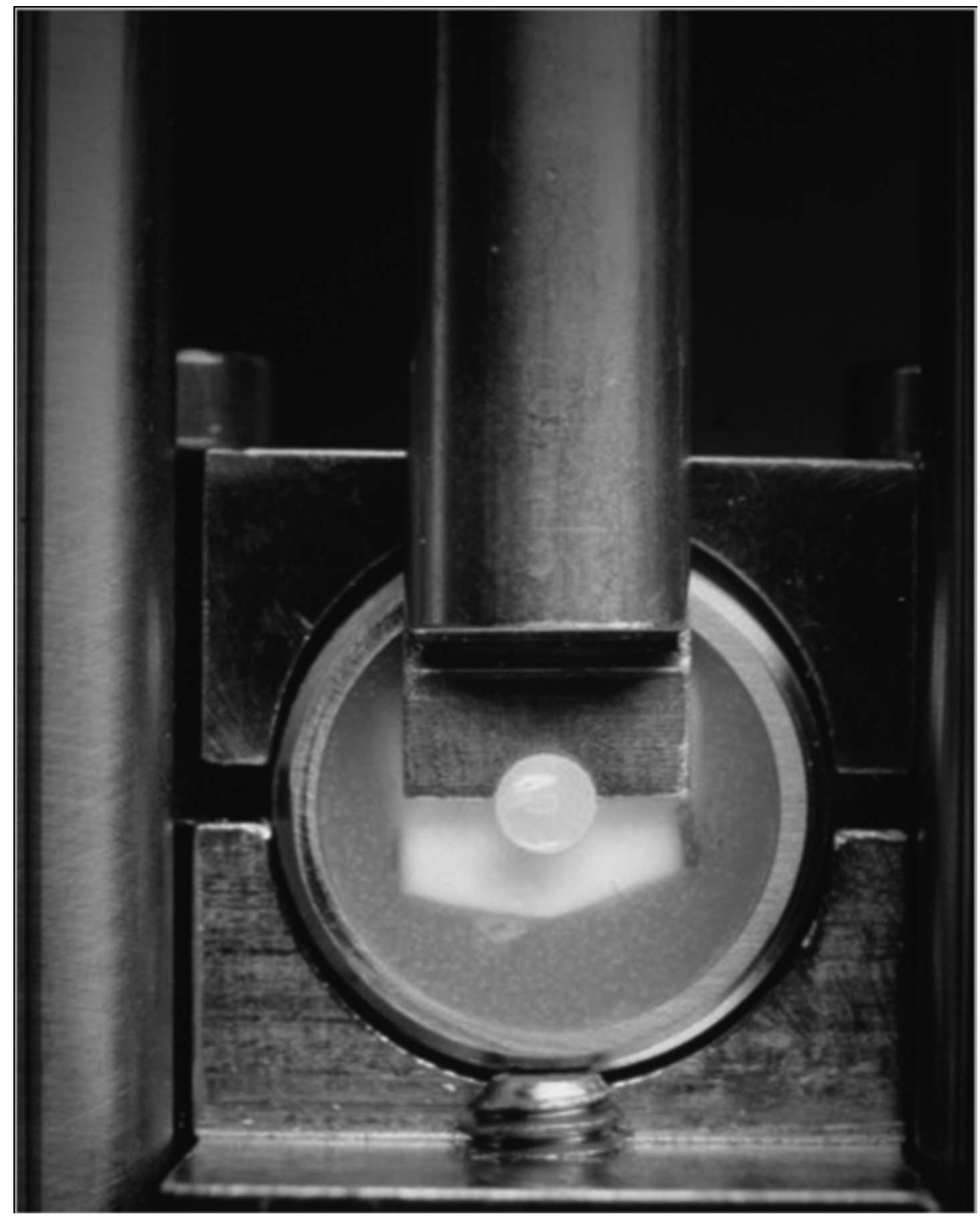


Figure 2. Mean values of shear bond strength as a function of thermocycling.

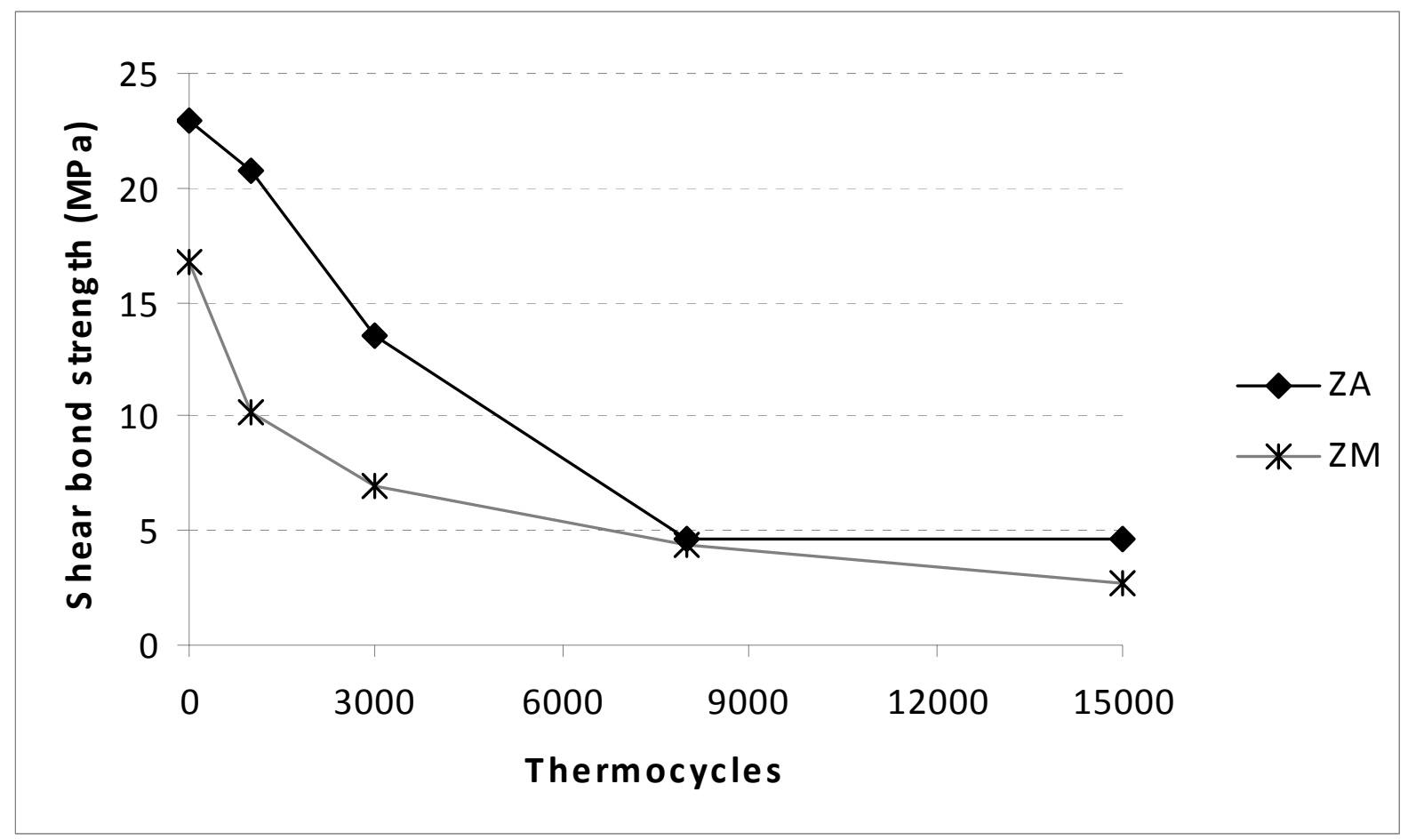

